\title{
Investigation of an Application/Usage of Information Technology in Learning of Cross-Cultural Diversity-a Study of Perception of the Indian Expatriates Across the Globe
}

\author{
Hamlata J. Bhat ${ }^{1}$ Anand Nayyar ${ }^{2, *}$
}

\begin{abstract}
${ }^{1}$ Department of Computer Science and Engineering, IILM College of Engineering and Technology, Greater Noida, India ${ }^{2}$ Graduate School, Duy Tan University, Da Nang, Viet Nam

*Corresponding author. Email: anandnayyar@duytan.edu.vn
\end{abstract}

\begin{abstract}
The Globalization era has transformed the world and international integration has risen from the interchange of world's outlook, products, ideas, and culture. Due to Globalization many MNCs have increased their investments worldwide. After the advent of "Information Technology", learning the Cross-cultural diversity became easy and more interpretable compared to the manually written article, because it contains visual, audio and text, and can be converted into one's own language, as well. In this context, the objectives of the study are divided into two parts. i.e. i) to investigate an application/usage of Information Technology in learning of cross-cultural diversity, ii) to analyze the Perception of Indian Expatriates on Cross-cultural diversity and learning through information technology. The perception of the respondents was examined with the use of statistical tools like percentage, measure of central tendency, chi-square test etc. Though this study, we reveal that learn the culture, language, social $t$ and political environment of any country is equally important for different age group, gender, income and qualified (educated) group of people. It has been proved in the hypothesis testing where, $5 \%$ significance value, i.e. $a=0.05$ are taken. The probability value ( $\mathrm{p}$ value) was always greater than its significant value in almost every case. To analyze the perception of Indian Expatriates on learnt the Cross-Culture Diversity though Information Technology provided positive result. The data reveal that average response of the respondent was closest to 5- and 4-point scale. It implies that technology help to NRI in learning the cultural diversity of the host country.
\end{abstract}

Keywords: Cross-cultural diversity, E-learning, Social Media, Information Technology, Communication, mobile, Cross-Culture Management, Skype, blogs, Twitter, Indian Expatriates, Portals

\section{INTRODUCTION}

Learning about cross cultural diversity has become very important for the corporate people due to extension growth of business in international platform. Understanding other countries-languages, work culture and socio-political culture are important for any organization now-a-days. The crosscultural diversity in an organization deals with understanding different business customs and their communication strategies. The communication is an important part of cross cultural environment. During communication, people are required to develop an understanding between each other. In Europe, country's economists think about the social, economical and organizational cultural diversity and develop the cultural-economic agenda to understand how human capital from across the border will helpful for the economic growth of the country by Enn Lun Yong [1].
The fast evolution of information technology \& communication, social networks and mobile platforms are transforming traditional ideas of community \& cross-cultural communication into new ways to distribute ideas and drive engagement. Now-a-day's companies have diversity in their work-force, for that they recruit more number of workmen from different corners of the world. MNCs are doing this because of the availability of skilled labor for higher wages in the local workforce. Learning about Cross-cultural diversity was initiated few decades back, when firms failed to sustain in the global market. But at that time, things were not that as much efficient as compared to now. The high cultural diversity is found in the cities. The venture or entrepreneur provides a new opportunity for the people. They are looking for the skillful employee/labor so that the employee can easily understand the diversified culture of the organizations; discussed by David B. Audretsch,Maksim, Belitski, Julia Korosteleva [2]. After the advent of "Information Technology", learning about cultural diversity became easy and more interpretable compared to the manually written 
article, because it contains visual, audio and text, and can be converted into one's own

language, as well. The main aim of this paper is to provide the real aspect of leaning the cross-culture diversity through IT. Therefore, the author has focused on the primary research more as compare to conception-based research. The first objective of this study is to investigate applications/usages of information technology in learning of cross-cultural diversity and second objective is to analyze the perception of Indian expatriates on learning cross-cultural diversity through information technology. In this study, the author has gathered information about the perception of Indian expatriates on learning cross-cultural diversity through information technology by issuing an online questionnaire. The questionnaires are divided into three parts i.e.

- Respondents personal profile

- Information Technology tools

- Effects of IT on Learning Cross Culture Diversity (CCD)

The Information Technology tools are classifieds in-to four categories, these are:

- E-Learning

- Social Media

- IT Devices (Apps \& E-mails)

- IT Knowledge and Skills

1.1 E-Learning: The e-Learning is an online platform to access an educational curriculum outside a traditional classroom. In this case various courses, program or degree delivered completely online. It is a teaching-learning process via the internet. The e-learning is also called a distance education, computerized electronic learning and internet learning. Thus, there are many online programs available for learning the cross-cultural diversity in a short span of time.

1.2. Social Media: The Social media connects online communication channels committed to community-based input, interaction, content-sharing and collaboration. This is a very popular medium among the young professionals to interact and communicate with the people across the globe in a cross-cultural environment.

1.3. IT Devices (Apps \& E-mails): An Information Technology devices, networking and applications are very helpful for learning the cross-cultural of different countries. The communication process has moved 'snail to mail'. For this internet has an important role in connecting people worldwide. An internet allows people leaving in different countries around the world to instantly contact through email, chat programs/apps and video calls. It helps in learning of cultural diversity of the country very well.

1.4 IT Knowledge and Skills: It has been observed that the technical person can easy grasp and understand the applications of technology in better manner There are many portals on internet world to learn. The Tec save person can easily find out the ways to learn and teach the cross culture. Hence, it is necessary for an individual to have IT knowledge and skills to explore the knowledge and utilize in their working.

a) In the third part of the study the author has examined the application/usage of information technology in learning of cross-cultural diversity (CCD)/culture and environment. b) In this paper author has used various statistical tools like frequency, percentage, mean, standard deviation and chisquare test etc. To get more understanding of the result, the author has also used the graphical methods for representation of the data.

\section{BACKGROUND}

The term "culture" represented as a qualities, ideas, and methods for living of individuals or social gathering. On the other words the "culture" can be derived into two ways. (i) The first is "Bland Culture", which is a common culture of all people living on this planet and (ii) the second is "Neighborhood Culture", which refer specific culture for a various geographical community, originations and social gathering. The more extensive meaning of the word "culture" is having two implications i.e. "human advancement which involves expressions and specialties, instruction and conduct" and another refer to the way "individuals think, feel and act as per the qualities and standards prevailing in their general public". When we talked about the Hofstede's cultural dimensions theory, it is a framework for crosscultural communication. According to this theory culture is characterized as "the aggregate programming of the brain recognizing the individuals from one gathering or class of individuals from another." Michael Jones, Irit Alony [3]. In the simple language we can say the culture refer to the qualities. A large portion of one's way of life is obtained amid youth, before pubescence. The people at an early age can retain social standards from their social environment, from guardians, kin, companion and so forth. Along these lines, cultural people group to work easily in a particular society. Therefore, there are different levels where a culture can existed and required to work.

2.1. National/societal level culture: This level of culture refers to the standard, behaviors, beliefs, customs, and values shared by the people of that county. It also revels the special characteristics in the way of their languages, ethnics, food, religion, urban, rural \& tribal identity, and history and traditions.

2.2. Organizational level culture: An organization's culture represented through its business practices and policies, employees' welfare, organizational hierarchy, peer-to-peer group relationship, boss-subordinate relationship, performance, behavior of individual and organizations' as a whole and the ways of utilization of resources.

2.3. Occupational level culture: The occupation level culture develops through the trade interchange i.e. import and export practices, social interaction, sharing knowledge and experience, work culture trainings, mutual support and sustainability and growth.

2.4 Gender level culture: The gender contrasts are perceived inside a similar culture, there is the thing that can be known as a man's culture that varies from a ladies' way of life. Actually, men and ladies can play out the same assignments in the working environment, yet they have contrasted with regards to reacting to the images utilized as a part of society. 
In the context of this study many researchers have contributed their task/research in the same area. Therefore, the highlights of few researchers are as follows:

In research article "Understanding cultural diversity and economic prosperity in Europe: a literature review and proposal of a culture-economy framework", the author has discussed the three permanents of cultural diversity i.e. cultural-diversity for the economic prosperity, development of the cultural-economic framework and understand the relationship of Asia-European countries. Enn Lun Yong [4]. In research article "Cultural diversity and knowledge in explaining entrepreneurship in European cities" authors discussed that in cities cultural diversity are very high. The Cities with large cultural diversity have great prospects for entrepreneurship and new venture in the area of technology and knowledge by David B. Audretsch, Maksim Belitski, Julia Korosteleva [5]. In the paper "Educational diversity and ethnic cultural heritage in the process of globalization", the author Junhao Zhang, discussed the features of educational development toward cultural diversity and analyze the relationship between education and ethnic cultures inheritance by Zhang, [6]. The authors in paper "Unraveling the effects of cultural diversity in teams: A meta-analysis of research on multicultural work groups", discussed about the cross-national vs intra-national of cultural diversity and its affect. This study was done with the help of meta-analysis by Stahl, G., Maznevski, M., Voigt, A. et al. [7]. In research article "The Diversity Quality Cycle: driving culture change through innovative governance" the author discussed about the impact of the design, introduction and application of the "Diversity Quality Cycle". Jude Smith Rachele[8]. In this paper author apply the Hofstede's cultural dimensions theory. An author discussed the significance of information system in the multiculturalism in today's business. Further, author highlighted how the explosion and essentiality of information systems, development and management of IS needs to be considered in light of the cultural factors which impact upon its utility. The paper finds support for the dimensions promoted by Hofstede in regard to information systems for learning the cross-culture diversity by Michael Jones, Irit Alony [9]. "An approach to understand cross-cultural information technology (IT) management issues that focus on the implicit aspects of culture is described and applied", in this paper, author design the theoretical framework to show how to understand cross-cultural IT management issues. The proposed concept is applied to an examination of the interplay among multiple contextual influences-the national cultures of the host and home countries, the IT industry culture, and the organizational culture of a particular firm, J.Y. Weisinger ; E.M. Trauth [10]. In the "Requirements gathering in information technology: A Cross-cultural perspective" discusses the importance of cross-cultural in IT projects and how to enhance intercultural perception/ thoughts. Further, author discussed the communication performance in environments where high levels of diversity are existed. Americo B. Cunha, Alberto G. Canen [11]. In the paper "Towards an Integrated IT Governance and IT Management Framework" the author discussed on leverage the IT Governance Contingency factors and its general guidelines. Later, the author provides and main IT
Governance and IT Management areas in order to provide a scientific approach by Ruben Pereira, Miguel Mira da Silva[12]. In paper author discuss the about the globalization culture and explain how advances in the field of information technology, liberalization in trade and investment have increased the ease and speed with which companies can manage their global operations. Author also talked about that due to globalization, many companies are now expanding their business in more than one country. The cross broader culture of business companies gives the birth of multicultural organization where employees from different countries work together. The aim of this paper is to find out these discrepancies and then suggest some effective solutions to manage effectively the cross-cultural aspect of human resources for the success of global business - Diwakar Singh [13]. In this paper, author discussed about how an organized multidisciplinary framework that defines the role of Information Communication Technology (ICT) in leveraging Intellectual Capital (IC) across borders in between head office and subsidiaries of Multinational Companies (MNCs). Further, the author investigates the strategic importance of ICT within MNC and also speaks to the transubstantiation of MNC into boundary less Global Knowledge-Based Organization. Furthermore, the paper suggests a new multinational ICT/IC governance strategy that handles the emerging complexities associated with the modern intangible assets reuse, synthesis and synergy. - (The role of Information Technology in the Advancement of Multinational Corporation's Intellectual Captain -Mona A. Mohamed[14]. In this paper the author has to explore the cultural context of information technology management in China: cultural tendency depends upon dynamic and power distance dimension and to apply them specifically to information technology management in China. In this regard, a large number of studies on the management and Chinese culture are cited. The author has investigated the five perspectives of information technology management i.e. information technology properties, information technology infrastructure, management roles, human resources management, and entering into strategic alliances. General lessons can be learned about the ways in which information technology is managed, or should be managed, in developing countries.-Binshan Lin [15]. The paper "Empirical Measurement of the Effects of Cultural Diversity on Software Quality Management", author discussed about the cross-cultural issues in Software Quality Management by Kerstin V. SiakasElli Georgiadou[16]. In paper "Knowledge Networking in Cross-Cultural Settings", the author has given more focused on collaboration between Indian and European a institutes and universities. Karamjit S. Gill [17].

\section{OBJECTIVES OF THE STUDY}

The main objectives of the study are:

3.1 To investigate applications / usages information technology in learning of cross-cultural diversity. 


\section{DATA ANALYSIS AND INTERPRETATION} learning Cross cultural diversity through information technology.

\section{SOME EXCLUSIVE HYPOTHESES}

4.1. Learning of "cross-culture diversity" through e- learning courses is independent from gender.

4.2. There is no relationship between Age and Learning of "cross-culture diversity" through e-learning

4.3. The occupation of the respondents does not have any influence on learning cross-culture diversity through e-leaning 4.4. The occupation of the respondents does not have any influence on learning cross-culture diversity through e-leaning 4.5. There is no relationship between Income and Learning of "cross-culture diversity" through e-learning

4.6. Age is independent from the learning of cross-cultural diversity through social media

4.7. Educational qualification not influence to learn the crossculture diversity through social media

4.8. Incomes and learn the cross-culture diversity through social media are independent.

4.9. There is no relationship between age and leaned through IT devices (apps/e-mails).

4.10. There is no association between occupation and IT knowledge \& skills.

\section{METHODOLOGY OF THE STUDY}

5.1. Universe of the study: The respondents of this study are the Indian Expatriates across the Globe.

5.2. Sampling: Sampling is random, convenient sampling method and the sample size is 30 .

5.3. Data Collection Techniques: The data was collection through primary and secondary sources.

5.4. Primary data are used for this research and the data collection work is done by conducting online survey through Google doc.

5.5. Secondary data sources are also utilized for the study. The secondary sources of information include brochures, printed reports, newspapers, various sites, books, magazines research study etc. Thus, the data collected from the above sources are utilized for this study.

5.6. Data Analysis Method: After completion of data collection task, the data were organized, tabulated \& analyzed. The tables \& graphs were prepared and interpretation was carried out for the purpose of analysis of data. Computer software SPSS and MS EXCEL is used and statistical tool also applied. Data are analyzed with:

- Percentage Analysis with graphical representation

- Mean and Standard deviations

- Graphs and Charts

- Chi-square test

\subsection{Testing Internal Consistent Reliability of data}

An investigating an applications/usage of Information Technology in learning Cross Cultural Diversity (CCD) is classified into five major categories i.e. E-learning, Social Media, IT devices/gadgets, Technical Knowledge \& Skills and Learned Cross Culture Diversity. The researchers have used the Cronbach Alpha as shown in Table-1, to test the internal consistent reliability of the data. As per the analysis of the result shown in table-1, the value of Cronbach's Alpha for the dimension "E-learning" is .851, "Social Media" is .751 , "IT devices/gadgets" is .760, "Technical knowledge and Skills is .755 and Learned Cross Culture Diversity" is .801. It implies that the internal consistencies of a multipleitem scale of all the dimensions are highly reliable in response in research.

\subsection{Analysis of the personal profile of the respondents}

As far as the demographic parameters of the respondents are concerned, the author has included the Age, Gender, Occupation, Name of the Host Country, Educational Qualification, Annual Income (in Rupees), and the Number of Years the Respondent Lived in the Host Country.

As per the analysis of the parameter age depicts in the table2 , we found that the $43.3 \%$ of the respondents are 20-30 age group, $20 \%$ are $31-40$ age and $36.7 \%$ are from $41-50$ age. There are no respondents from the $51 \&$ above age group. In the further analysis, it reveals that the maximum numbers of respondents are from 20-30 age groups in the study.

As per the analysis of the gender the data shows that there are $60 \%$ male and $40 \%$ female.

In the category of occupation, $33.3 \%$ are IT professionals, $10 \%$ are from academics, $13.3 \%$ are consultants, $6.7 \%$ are engineers, $16.7 \%$ are housewives, $3.3 \%$ are students and $16.7 \%$ are others. In the analysis further, it is revealed that maximum number of respondents is IT professionals. Further, we found that $50 \%$ of the respondents are living in USA, $16.7 \%$ in UAE, $20 \%$ in UK and $13.3 \%$ of the Indian Expatriates live in Australia. In this study we have received the maximum response from USA.

In the category of Educational Qualification, 3.3\% are under graduate, $36.7 \%$ are graduate, $50 \%$ are post graduates and $10 \%$ are above post graduates in the study.

In case of Annual Income (i.e. asked in Indian Currency), $40 \%$ of the respondents are from 0-500000 income group, $16.7 \%$ of respondents are 500001-1000000 income group and $43.3 \%$ of the respondents are from above 1500000 income categories in the study.

In case of variable number of years lived in the host country, the data reveals that $53.3 \%$ of the Indian expatriates have lived $0-5$ years abroad, 3.3\% have lived since 6-10 years, 
$16.7 \%$ have lived $11-15$ years, $23.3 \%$ have lived $16-20$ years and $3.3 \%$ of the respondents have been living $21 \&$ above years outside India.

Table 1 Testing Internal Consistent Reliability of data

\begin{tabular}{|c|c|c|}
\hline Dimensions & Variable & $\begin{array}{c}\text { Cronbach's } \\
\text { Alpha }\end{array}$ \\
\hline E-Learning & $\begin{array}{l}\text { a) Is E-learning portal covering all the aspects of cross-cultural diversity? (Usually, } \\
\text { cultural diversity takes into account language, work culture, social-political, } \\
\text { religion, race, sexual, orientation, age and ethnicity etc.). } \\
\text { b) Is E-learning more relevant portal to understand the cultural diversity of other } \\
\text { countries as compared to class-room coaching? } \\
\text { c) Are E-learning apps easy access on the devices like mobile, laptop and iPod etc? } \\
\text { d) Is an E-learning portal providing a relevant video/study materials and assignment for } \\
\text { learning the culture diversity? } \\
\text { e) Is the company/employer providing training on to learn the cultural diversity of the } \\
\text { host country of their employees through e-learning? }\end{array}$ & .851 \\
\hline $\begin{array}{l}\text { Social } \\
\text { Media }\end{array}$ & $\begin{array}{l}\text { a) Is social media giving a closer look to the host countries cultural diversity? } \\
\text { b) Is the Facebook social site more relevant as compared to other social sites for } \\
\text { frequently interacting and communicating with different types of people to learn } \\
\text { their culture? } \\
\text { c) Is interaction with people through social media giving a glimpse of the host country } \\
\text { customs \& traditions? } \\
\text { d) Is a professional site like LinkedIn helping to understand the host country's cultural } \\
\text { e) Is information through social media won't help in the learning of cultural diversity }\end{array}$ & .751 \\
\hline $\begin{array}{l}\text { IT Devices } \\
\text { (Apps \& } \\
\text { E-mails) }\end{array}$ & $\begin{array}{l}\text { a) you willing to connect through IT devices (mobile/laptop) applications with } \\
\text { your colleagues across the globe? } \\
\text { b) Is there ready availability of software at the company/workplace for cross cultural } \\
\text { training and is it helpful too? } \\
\text { c) Is use of mobile device, creating a hindrance in learning cross-cultural diversity? } \\
\text { d) Have you learned all the cultural and sub-cultural practices of the host country } \\
\text { through IT devices/apps/e-mails? } \\
\text { e) Are you frequently using gadgets/devices to check the messenger apps, e-mails and } \\
\text { what app, etc. to see the important messages received from the colleagues across the } \\
\text { globe? }\end{array}$ & .760 \\
\hline $\begin{array}{l}\text { Technical } \\
\text { Knowledge } \\
\text { and Skills }\end{array}$ & $\begin{array}{l}\text { a) Is it necessary to have technical knowledge to the learning about cross cultural } \\
\text { diversity through IT? } \\
\text { b) Is there quite difference in between the direct and indirect (through electronic media) } \\
\text { interaction? } \\
\text { c) Are you frequently reading or subscribed to a blog for learning cross-culture? } \\
\text { d) Are online courses are perfect way for language learning? } \\
\text { e) Are IT aid/devices/applications not always the best solution for cross-culture } \\
\text { learning? }\end{array}$ & .755 \\
\hline $\begin{array}{c}\text { Effects of IT } \\
\text { on Learning } \\
\text { Cross Culture } \\
\text { Diversity } \\
\text { (CCD) }\end{array}$ & $\begin{array}{l}\text { a) Are there any discrepancies/gaps I find after learning the cultural diversity of Host Country } \\
\text { though IT from the practical/real culture? } \\
\text { b) Can I say that Information Technology devices \& aids are enough to have knowledge about the } \\
\text { Host country cultural diversity? } \\
\text { c) Have I adjusted well to the culture of the Host Country that I am staying in? } \\
\text { d) Did it take long for me to learn the Cultural diversity of the country that I am staying in? } \\
\text { e) Do I think that the barriers to communicate across the world have mitigated/reduced due to the } \\
\text { advent/advance of IT? } \\
\text { f) Does IT assist me to understand the bureaucratic/autocratic/democratic (as applicable) cultural } \\
\text { diversity of the Host country? }\end{array}$ & .801 \\
\hline
\end{tabular}

Source: Authors own compilation from the primary data 
Table 2 Analysis of the personal profile of the respondents

\begin{tabular}{|c|c|c|c|}
\hline Variables & Categories & Frequency & Percent \\
\hline \multirow{4}{*}{ Age } & $20-30$ & 13 & 43.3 \\
\hline & $31-40$ & 6 & 20.0 \\
\hline & $41-50$ & 11 & 36.7 \\
\hline & $51 \&$ above & 00 & 00 \\
\hline \multirow[t]{2}{*}{ Gender } & Male & 18 & 60.0 \\
\hline & Female & 12 & 40.0 \\
\hline \multirow{7}{*}{ Occupation } & IT Professional & 10 & 33.3 \\
\hline & Academician & 3 & 10.0 \\
\hline & Consultant & 4 & 13.3 \\
\hline & Engineers & 2 & 6.7 \\
\hline & House wife & 5 & 16.7 \\
\hline & Students & 1 & 3.3 \\
\hline & Others & 5 & 16.7 \\
\hline \multirow[t]{4}{*}{ Host Country } & USA & 15 & 50.0 \\
\hline & UAE & 5 & 16.7 \\
\hline & UK & 6 & 20.0 \\
\hline & Australia & 4 & 13.3 \\
\hline \multirow{4}{*}{$\begin{array}{l}\text { Educational } \\
\text { Qualification }\end{array}$} & Under Graduate & 1 & 3.3 \\
\hline & Graduate & 11 & 36.7 \\
\hline & Post Graduate & 15 & 50.0 \\
\hline & Above Post Graduate & 3 & 10.0 \\
\hline \multirow{3}{*}{$\begin{array}{l}\text { Annual Income } \\
\text { (in Rupees) }\end{array}$} & $0-500000$ & 12 & 40.0 \\
\hline & $500001-1000000$ & 5 & 16.7 \\
\hline & above 1500000 & 13 & 43.3 \\
\hline \multirow{5}{*}{$\begin{array}{l}\text { Number of years lived } \\
\text { in host country }\end{array}$} & $0-5$ & 16 & 53.3 \\
\hline & $6-10$ & 1 & 3.3 \\
\hline & $11-15$ & 5 & 16.7 \\
\hline & $16-20$ & 7 & 23.3 \\
\hline & $21 \&$ above & 1 & 3.3 \\
\hline
\end{tabular}

Source: Authors own compilation from the primary data)

Table 3 Analyze the perception of Indian Expatriates on learning Cross Culture Diversity

\begin{tabular}{|c|c|c|c|c|c|}
\hline \multicolumn{7}{|c|}{ Analysis of the perception on the bases of Mean and SD } \\
\hline Parameters & N & Minimum & Maximum & Mean & Std. Deviation \\
\hline E-Learning & 30 & 2.40 & 5.00 & 4.0267 & .65964 \\
\hline Social Media & 30 & 2.40 & 4.80 & 3.5867 & .54566 \\
\hline IT Devices (Apps \& E-mails) & 30 & 2.20 & 4.20 & 3.3267 & .43781 \\
\hline IT knowledge and skills & 30 & 2.80 & 4.80 & 3.6733 & .47411 \\
\hline
\end{tabular}




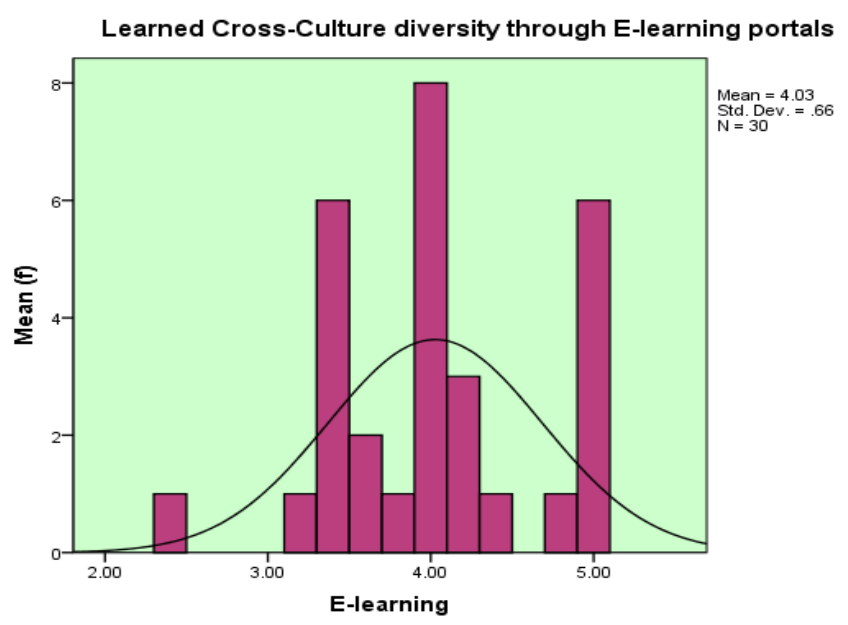

Figure 1 Graph-1: E-Leaning portal

Source: Authors on compilation from primary data

E-learning across the corporate world is growing rapidly. However, taking into consideration the cultural barriers to learning, we asked certain questions to the respondents (Indian Expatriates) across the globe to examine that how e-learning portals are helpful for them to learn the culture of the host country where they have immigrated, are given below.

a) Are E-learning portals covering all the aspects of cross-cultural diversity? (Usually, cultural diversity takes into account language, work culture, social-political, religion, race, sexual, orientation, age and ethnicity etc.)?

b) Is E-learning more relevant a portal to understand the cultural diversity of other countries as compared to class-room coaching?

c) Are E-learning apps easily accessible on the devices like mobile, laptop and iPod etc?

d) Is an E-learning portal providing a relevant video/study material and assignment for learning the culture diversity?

e) Is the company/employer providing training to learn the cultural diversity of the host country of their employees through e-learning?

With an average response of the respondent was 4.02 (show in table-3, graph-1). It is concluded that the average numbers of respondents agree on the questions that were asked to them. On the other hand, the standard deviation (SD) value is 0.66 . It specifies that somewhere the opinion of the respondent has little variation.

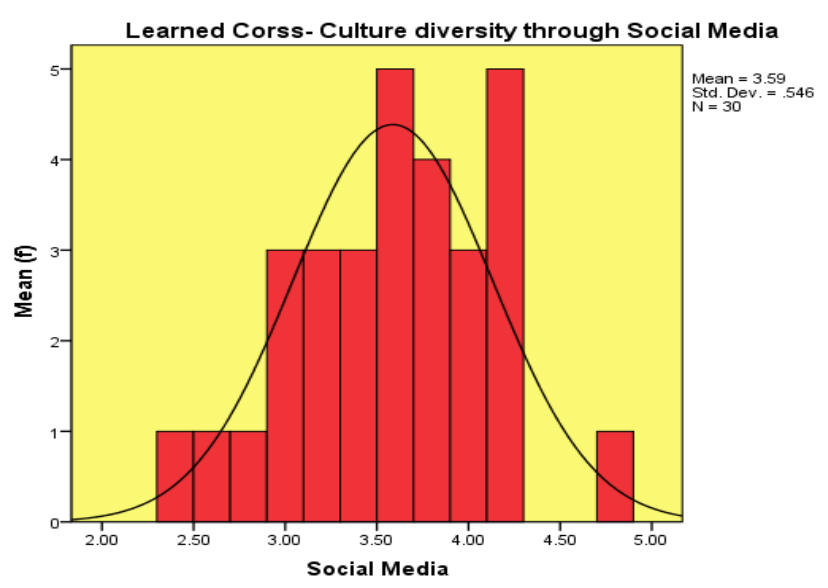

Figure 2 Graph-2: Social Media

Source: Authors on compilation from primary data

Social media is the powerful instrument that helps in communicating and interacting with people. It is a medium for social interaction, using highly accessible and scalable communication. Facebook and LinkedIn are most popular among young professionals and help employees remain focused on and aligned with corporate objectives and also learn the cultural diversity to connect with people across the globe. In this connection, we have asked a few questions to our respondents and let to know that how social media sites are useful to break the cultural barriers, are as follows:

a) Is social media giving a closer look to the host countries cultural diversity?

b) Is the Facebook social site more relevant as compared to other social sites for frequent interaction and communication with different types of people to learn their culture?

c) Is interaction with people through social media giving a glimpse of the host country customs \& traditions?

d) Is a professional site like LinkedIn helping to understand the host country's cultural diversity?

e) Is information through social media won't help in the learning of cultural diversity.

f) As per our study shows in Table-3, graph-2), the average response of the respondents are 3.58 , it is close to the average value of 4 . It implies that the average numbers of respondents are having the same opinion that social media sites help in to learn cross cultural diversity. On the other hand, the standard deviation (SD) value is 0.55 . It specifies that somewhere the opinion of the respondent has little variation. 


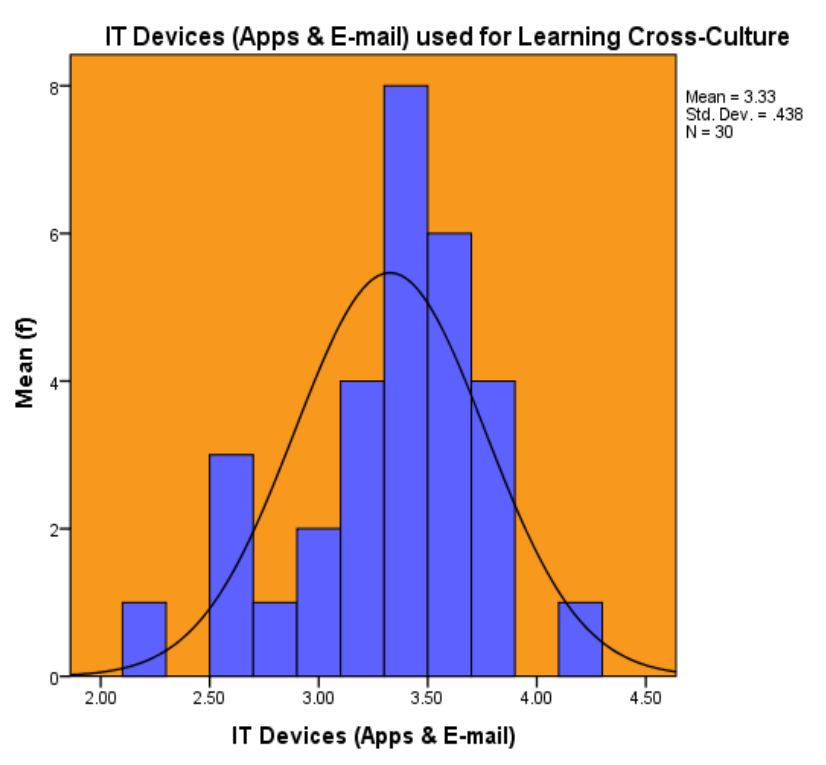

Figure 3 Graph-3: IT Devices (Apps \& E-mails)

Source: Authors own compilation from the primary data

The last few decades have seen spectacular developments in the area of information technology. The way of communication has moved 'snail to mail'. The internet plays an important role in connecting people world-wide. It allows people leaving around the world to instantly contact each other via email, chat programs/apps and video calls and video conferencing. In this association, we have asked a few questions (mentioned below) to our respondents and evaluated that IT devices and chat applications are helpful to learn the cross-cultural diversity.

a) Are you willing to connect through IT devices (mobile/laptop) applications with your colleagues across the globe?

b) Is there ready availability of software at the company/workplace for cross cultural training and is it helpful too?

c) Is use of mobile device, creating a hindrance in learning cross-cultural diversity?

d) Have you learned all the cultural and sub-cultural practices of the host country through IT devices/apps/emails?

e) Are you frequently using gadgets/devices to check the messenger apps, e-mails and what app, etc. to see the important messages received from the colleagues across the globe?

The research reveals that (Table- 3 graph-3), the average response of the respondent are 3.33, It implies that the average number of respondents are having neutral opinion. The respondent thinks that somehow IT devices \& applications are useful to learn the cross-cultural diversity management but somewhere they don't feel the same. On the other hand, the standard deviation (SD) value is 0.44 , it denotes that whatever the opinion of the respondent it has little variation.

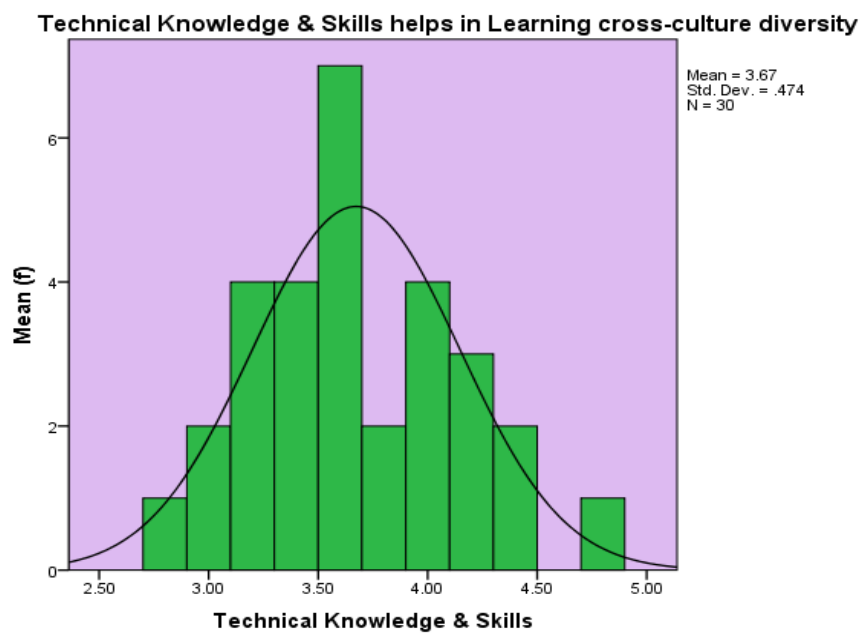

Figure 4 Graph-4: Technical Knowledge \&Skills

Source: Authors own compilation from the primary data

Technical knowledge relates to knowledge about modern technology, its working and advances. On the other hand, Technical skills are abilities to perform some specific tasks. In the age of Internet, there are various technical methods in the form of applications/ learning portals/ various media of communication across the globe. It is necessary for an individual to have the knowledge and skills to explore and utilize in their working. Today, people can learn the cross-cultural diversity management through technology. In this study, our one of the objectives is to be acquainted with, how technical knowledge and skills help in learning. In this context we asked few questions to our respondents which are as follows:

a) Is it necessary to have technical knowledge to the learning about cross cultural diversity through IT?

b) Is there quite difference in between the direct and indirect (through electronic media) interaction?

c) Are you frequently reading or subscribed to a blog for learning cross-culture?

d) Are online courses the perfect way for language learning?

e) Are IT aid/devices/applications are not always the best solution for cross-culture learning?

As per our study shown in (Table-3, graph-4), the average response of the respondents are 3.66, it is close to the average value of 4 . It implies that the average numbers of respondents are having the same opinion that technical knowledge and skills help more in learning cross-cultural diversity. On the other hand the standard deviation (SD) value is 0.47 . It specifies that somewhere the opinion of the respondent has little variation. 


\subsection{Analyzing the effects of learning cross- culture diversity (CCD) through IT platforms}

We live in different cross-cultural environment. It is found that the people (corporate people and their family), will face the lot of challenges to interact with peers when they are living or deputed in other country. They have to learn the culture of that country and develop the skills and understanding of how to be curious of others, how to ask questions, how to listen, how to explore and value differences and similarities, and how to articulately communicate their own lives to those variants for themselves, will thrive. Today, Information Technology platforms play a vital role to the people to learn the crossculture diversity. The data in the (Table-4, Graph-5) show for the parameter "Discrepancy/gap in learning through IT platforms" the mean score is rated 3.33. It means that on an average respondent having given a neutral opinion in this respect. On the other hand, SD value 1.40 is very high. It implies that the variations in opinion of the respondents are very far. In case of the second parameter "IT devices/apps are enough to get the knowledge of the host country", the average is rated 2.53. It implies that the response of respondents was in between disagreed to neutral. It means few respondents have neutral and few are totally disagreed with this statement. When we examine the value of SD (i.e.1.55), it shows that the opinions of respondents are highly diverging. Further, in case of parameter "Adjust the culture of host country after learning through IT" is concerned, the mean score is 4.33 .
It shows that the respondents are agreeing that somehow IT platforms helped them in learning within the crosscultural environment and they are adjusted in the host country. In case of parameter "Long time taken to learn the CCD" the mean score is 2.07. It means that on average respondents are disagreeing with this statement. On the other hand, the SD is high i.e. 1.45, it implies that there is a huge variation in the opinion of one respondent to another. In case of parameter "Barriers of communication reduced due to the advent/advance of IT" the mean score is 4.27 and $\mathrm{SD}$ value is 1.34 . It has been interpreted that respondents are agreeing that information technology has reduced the barriers of communication and learning of cross-cultural diversity but on the bases of SD value the deviation occurs in the opinion. As per analysis of the parameter "IT assists to understand the bureaucratic/autocratic/democratic culture diversity of the host country", the mean scores are recorded 4.33 and SD is 1.09 . It construed that people are agreeing that IT assist to understand the bureaucratic/autocratic/democratic culture diversity of the host country. But on the basis of SD score, somewhere opinion varies in relation of the statement.

Table 4 Analyzing the effects of learning cross-culture diversity (CCD) through IT platforms

\begin{tabular}{|c|l|c|c|}
\hline S.no. & Parameters & Mean Score & SD \\
\hline 1 & Discrepancy/gap in learning through IT platforms & 3.33 & 1.40 \\
\hline 2 & IT devices/apps are enough to get the knowledge of host country & 4.33 & 1.21 \\
\hline 3 & Adjust the culture of host country after learning through IT & 2.07 & 1.45 \\
\hline 4 & Long time taken to learn the CCD & 4.27 & 1.34 \\
\hline 5 & Barriers of communication reduced due to the advent/advance of IT & 4.33 & 1.09 \\
\hline 6 & $\begin{array}{l}\text { IT assist to understand the bureaucratic/autocratic/democratic culture } \\
\text { diversity of the host country }\end{array}$ & \\
\hline
\end{tabular}

Source: Authors on compilation from primary data 


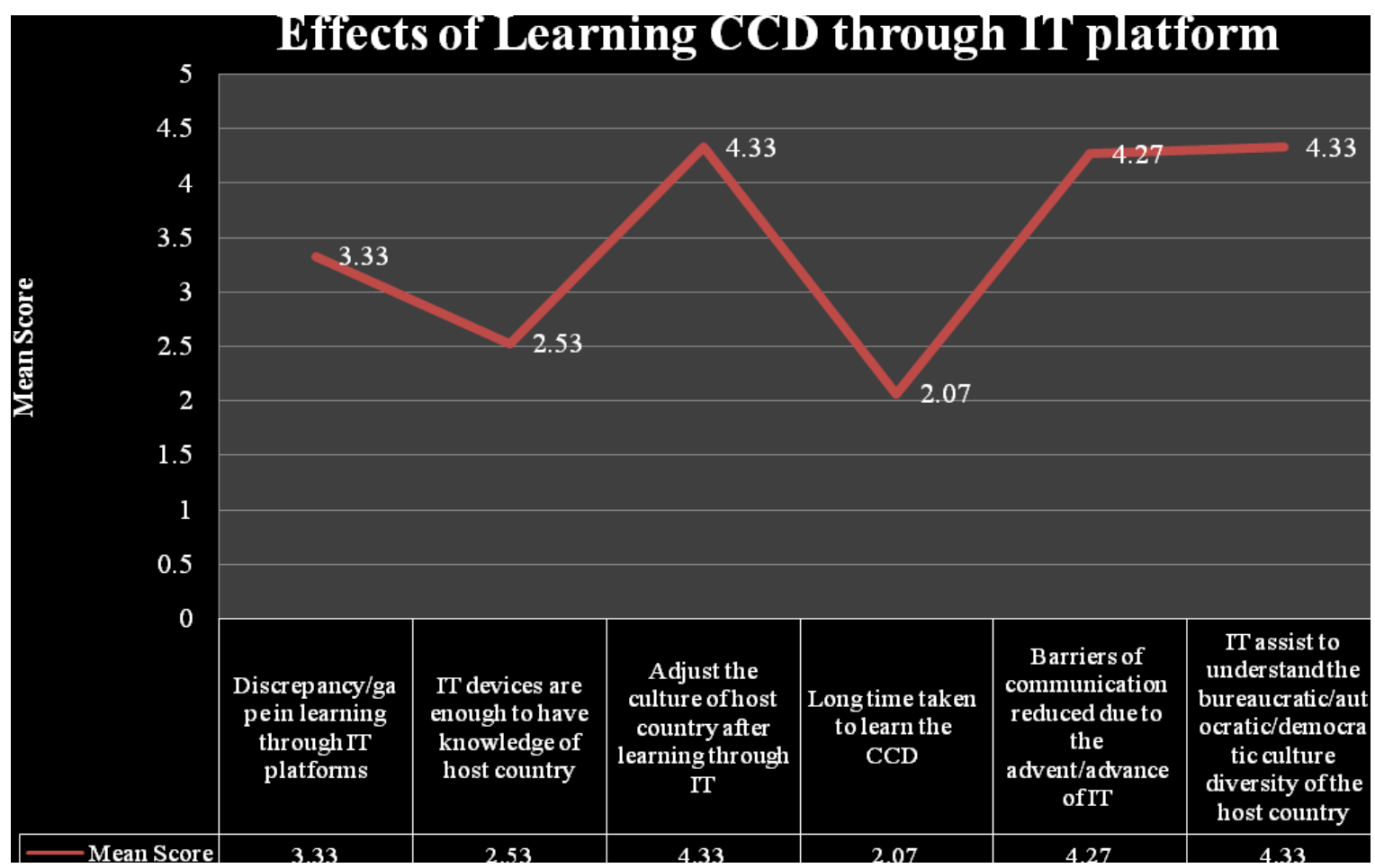

Figure 5 Graph-5: Effects of learning cross-culture diversity (CCD) through IT platforms

Source: Author sown compilation from the primary data

\section{HYPOTHESIS}

\subsection{Statement -1: Assessment of the association between gender and E-learning}

Let us assume that,

H0 = Learning of "cross-culture diversity" through elearning courses are independent from gender.

$\mathrm{H} 1$ = Learning of "cross-culture diversity" through elearning courses are independent from gender.

Result: As per the result we found that, calculated chisquare value is $X^{2}=10.382$ at a $5 \%$ significance value i.e. $\mathrm{a}=0.05$ and $\mathrm{p}$-value $=0.320$. It implies that $\mathrm{p}$ value is greater than its significance value. Hence, the null hypothesis (Ho) is not rejected. It has been concluded that learning the cross-culture diversity through e-learning courses are important to male as well as female.

\subsection{Statement -2: Examine the relationship between age and E-learning}

$\mathrm{H} 0=$ There is no relationship between Age and Learning of "cross-culture diversity" through e-learning $\mathrm{H} 1$ = There is a relationship between Age and Learning of "cross-culture diversity" through e-learning Learning of "cross-culture diversity" through e-learning

Result: As per the result we found that, calculated chisquare value is $\mathrm{X}^{2}=22.767$ at a $5 \%$ significance value i.e. $\mathrm{a}=0.05$ and $\mathrm{p}$-value $=0.200 \mathrm{It}$ implies that $\mathrm{p}$ - value is greater than its significance value. Hence, the null hypothesis (Ho) is not rejected. It has been concluded that learning the cross-cultural diversity through elearning courses are important for all the age group.

\subsection{Statement -3: Evaluating the influence of occupation on the E-learning of cross-culture}

Let us assume that,

$\mathrm{HO}=$ The occupation of the respondents are not having any influence on learning cross-culture diversity through e-leaning

$\mathrm{H} 1$ = The occupation of the respondents are having any influence on learning cross-culture diversity through eleaning 
Let us assume that,

$\mathrm{H} 0=$ Age is independent from the learning of crosscultural diversity through social media

$\mathrm{H} 1=$ Age is not independent from the learning of crosscultural diversity through social media

Result: As per the result we found that, calculate chisquare value is $\mathrm{X}^{2}=24.839$ at a $5 \%$ significance value i.e. $a=0.05$ and $p$-value $=0.208$ It implies that $p$-value is greater than its significance value. Hence, the null hypothesis (Ho) is not rejected. It has been concluded that learning the cross-culture diversity through social media is not limited to age.

\subsection{Statement -7: influence of Educational qualification on learning in the cross-cultural diversity through social media}

$\mathrm{H} 1$ = The occupation of respondents are having any influence on learning cross-cultural diversity through elearning

Result: As per the result we found that, calculate chisquare value is $X^{2}=61.229$ at a $5 \%$ significance value i.e. $a=0.05$ and $p$-value $=0.233$ It implies that $p$-value is greater than its significance value. Hence, the null hypothesis (Ho) is not rejected. It has been concluded that learning the cross-cultural diversity through elearning resources are not having any influence on particular education qualification. It is important for all.

\subsection{Statement -5: Examine the relationship between Annual Income and E-learning}

Let us assume that,

$\mathrm{H} 0=$ There is no relationship between Income and Learning of "cross-culture diversity" through e-learning

$\mathrm{H} 1$ = There is a relationship between Income and Learning of "cross-culture diversity" through e-learning

Result: As per the result we found that, calculate chisquare value is $X^{2}=18.609$ at a $5 \%$ significance value i.e. $a=0.05$ and $p$-value $=0.416$ It implies that $p$-value is greater than its significance value. Hence, the null hypothesis (Ho) is not rejected. It has been concluded that learning the cross-culture diversity through elearning courses are not having any influence on particular income group.

\subsection{Statement -6: Examine the relationship between Age and social media helps in understanding cross-cultural diversity.}

Let us assume that,

$\mathrm{H} 0$ = Educational qualification has no influence on learning in the cross-cultural diversity through social media

$\mathrm{H} 1$ = Educational qualification has influence on learning in the cross-cultural diversity through social media Result: As per the result we found that, calculate chi-square value is $\mathrm{X}^{2}=30.048$ at a $5 \%$ significance value i.e. $a=0.05$ and $p$-value $=0.463$. It implies that $p$ value is greater than its significance value. Hence, the null hypothesis (Ho) is not rejected. It has been concluded that any specific educational qualification does not influence learning in the cross-cultural diversity through social media. Every educated person can interact others and learn about cross cultural management.

\subsection{Statement -8: Examine the relationship between incomes and learn the cross-cultural diversity through social media}

Let us assume that,

$\mathrm{H} 0=$ Incomes and learning about the cross-cultural diversity through social media are independent

$\mathrm{H} 1$ = Incomes and learning about the cross-cultural diversity through social media are dependent

Result: As per the result we found that, calculate chisquare value is $X^{2}=21.733$ at a $5 \%$ significance value i.e. $a=0.05$ and $p$-value $=0.355$. It implies that $p$ - value is greater than its significance value. Hence, the null hypothesis (Ho) is not rejected. It has been concluded Incomes and learning about the cross-cultural diversity through social media are independent. 


\subsection{Statement -9: Examine the relationship between age and leaned through IT devices (apps/e-mails)}

Let us assume that,

$\mathrm{H} 0=$ There is no relationship between age and learning through IT devices (apps/e-mails)

$\mathrm{H} 1=$ There is a relationship between age and leaning through IT devices (apps/e-mails)

Result: As per the result we found that, calculate chisquare value is $\mathrm{X}^{2}=22.922$ at a $5 \%$ significance value i.e. $a=0.05$ and $p$-value $=0.116$. It implies that $p$ - value is greater than its significance value. Hence, the null hypothesis (Ho) is not rejected. It has been concluded that there is no relationship between age and learned through IT devices (apps/e-mails) etc.

\subsection{Statement -10: Evaluate the association between occupations and IT knowledge \& skills}

Let us assume that,

$\mathrm{HO}=$ There is no association between occupation and IT knowledge \& skills

$\mathrm{H} 1=$ There is association between occupation and IT knowledge \& skills

Result: As per the result we found that, calculate chisquare value is $X^{2}=31.312$ at a $5 \%$ significance value i.e. $a=0.05$ and $p$-value $=0.259$. It implies that $p$ - value is greater than its significance value. Hence, the null hypothesis (Ho) is not rejected. It has been concluded that there is no relationship between occupation and IT knowledge and skills.

\section{MAJOR FINDINGS}

The major findings of this study are as follows:

8.1. In this study the internal consistencies of a multiple-item scale of all the dimensions are more than 0.75. It means there is high reliability in response in research.

8.2. As per the analysis of the personal profile of the respondents, the author found that the maximum responses are received from the 20-30 age group. The male respondents are large in the study.

8.3. In case of educational qualification, the IT professionals are maximum to give the response. The replies from Indian Expatriates living in the USA are more as compared to other countries. In this study, maximum number of post graduates responded and in case of income, 15,00,000 and above income (Indian currency) group, were more to reply the questions. The maximum number of people, who lived 0-5 years abroad, forms the large population in this study.

8.4. In case use of IT tools for understanding the crossculture diversity, the maximum responses are for the elearning. The people think that online courses are more convenient to learn the cross-culture. On the second position IT knowledge and skills are required to learn the cross-culture and on third ranking is given to IT devices (apps \& e-mails). At last as per the opinion of the respondent's social media is useful to learn. An overall response of the respondents was rated in between agreed i.e. 4 rating scale to neutral i.e. 3 rating scale.

8.5. In case of the effects of learning about crosscultural diversity (CCD) through IT platforms is concerned, the maximum rating is given to the parameter "Adjust the culture of host country after learning through IT" and the parameter "IT assist to understand the bureaucratic/autocratic/democratic culture diversity of the host country".

8.6. For the parameter "Long time taken to learn the CCD", the respondents are rated very low. It means the people are not disagreed with this statement.

8.7. In the case of parameter "IT devices/apps are enough to get the knowledge of host country", the respondents are rated low score. It implies people are disagreed that IT devices/apps are enough to get knowledge of the host country.

8.8. In statement-1 of the hypotheses, it has been concluded that learning about the cross-cultural diversity through e-learning courses are important to male as well as female.

8.9. In statement- 2 of the hypotheses, it has been concluded that learning about the cross-cultural diversity through e-learning courses are important for all the age group.

8.10. In statement-3 of the hypotheses, it has been concluded that learning about the cross-cultural diversity through e-learning courses does not have any influence on particular occupation sector. It is important for all.

8.11. In statement-4 of the hypotheses, it has been concluded that learning about the cross-cultural diversity through e-learning courses is not having any influence on particular education qualification. It is important for all.

8.12. In the statement -5 of the hypotheses, it has been concluded that learning about the cross-cultural diversity through e-learning courses does not have any influence on particular income group.

8.13. In statement- 6 of the hypotheses, it has been concluded that there is no age limit for learning about the cross-culture diversity through social media.

8.14. In statement-7 of the hypotheses it has been concluded that any specific educational qualification does not influence learning about the cross-cultural 
diversity through social media. Every educated person can interact to other and learn the about cross-cultural diversity.

8.15. In statement- 8 of the hypotheses, it has been concluded Incomes and learning about the crosscultural diversity through social media are independent. 8.16. In statement-9 of the hypotheses, it has been concluded that there is no relationship between age and learned through IT devices (apps/e-mails) etc.

8.17. In statement-10 of the hypotheses, it has been concluded that there is no relationship between occupation and IT knowledge and skills.

\section{RECOMMENDATIONS}

9.1. To keep few points in mind when we interact and communicate with others in the organization, i.e. to keep an open mind, explore the knowledge of people's cultural backgrounds, develop the habits of active listening, observed carefully non-verbal communication, and maintain a personal touch.

9.2. The Internet and modern technology have opened up new market places that allow people to promote the businesses to new geographic locations and cultures. There should be proper knowledge of the same. There should be workshops and seminars organized so that people can get aware on how technology is used for learning purposes.

9.3. There are many social media platforms, where people interact and communicated the mass across the globe. Now-a-days these sites are not only for just a fun, it helps people to learn more.

9.4. Understanding the cultural diversity in the form of communication are major challenges to the workplace. In such cases, an effective communication Information Technology app should be used to remove the communication barriers from different cultures and backgrounds.

9.5. However, some basic learning about the culture and at-least something about the language of communication in different countries is important. The companies should provide proper training to the employees to learn about different cultures of that county either through video conferencing or some other electronic media.

9.6. Information Technology makes it easy to access the information at any time. Both the employee and the company use Information Technology to acquire and exchange the knowledge on cross-cultural diversity. The company should provide the visual and audio sessions to their employees to learn about different cultures.

9.7. There should be technology integration system to learn the cross-culture diversity. The tools of technology integration are computers, mobile devices like smart phones and tablets, digital cameras, social media platforms and networks, software applications, the Internet, etc. in daily training \& leaning practices. The successful technology integration are required a routine and transparent practices, accessible and readily available for the task at hand, supporting the training goals, and helping the people/employee to effectively understand the cross-cultural diversity.

9.8. The people should frequently explore through Internet. The online environment provides digitized course materials to understand the culture. And various tools like Skype allow synchronous communications, while blogs and Twitter can encourage asynchronous interaction.

\section{CONCLUSION}

The globalization era has transformed the world and international integration has risen from the interchange of world's outlook, products, ideas, and culture. Due to Globalization many MNCs have increased their investments worldwide. The learning the cross-cultural diversity is important now-a-days to companies due to the growth of global business, technology, and the internet. To understanding other countries languages, work culture, social-political culture are important for any organization that has a diverse workforce or plans on conducting global business. After the advent of "Information Technology", learning across cultures became easy and more interpretable compared to the manually written article, because it contains visual, audio and text, and can be converted into one's own language, as well. E-learning across-cultures in the corporate world are growing rapidly. Social media is that helps the most in communicating and interacting with people. It is a medium for social interaction, using highly accessible and scalable communication. Facebook and LinkedIn are most popular among young professionals and help employees remain focused on and aligned with corporate objectives and also learned the cultural diversity to connect with people across the world. There is an amazing development in the area of information technology. The internet plays an important role in connecting people. Through internet people in countries around the world can instantly contact each other via email, chat programs/apps and video calls etc. The technical knowledge and technical skills are required to perform some specific tasks and understand the depth of the concepts. In the age of Internet, there are various technical methods in the form of applications/ learning portals/ various media of communication across the globe. It is necessary for an individual to have knowledge and skills to explore and utilize in their working. Today, people can learn about cross-cultural diversity through technology.

The conclusion of this study is that Information Technology plays an important role to learn and 
to attend the regular classes. This study is also help to MNCs. They provide training to their employee with the help of technologies in an appropriate way.

helps the corporate world to view the changes happened in the global market scenario day basis. The different software packages and hardware helps the people to get their job done faster. The Information technology has improved the knowledge of people and also provides an easy access to different learning resources. They help to improve learning abilities of the people. These learning resources include audio, visual, online sessions, through social media, apps, etc. At the end, we can say that in today's scenario learning and accruing the knowledge in culturally diverse environment is difficult without Information Technology.

In this study, we found that Information Technology someway overcome the problems to understand the cross-cultural diversity and on the other hand many online programmes/ e-learning courses have provided practical training, research and theoretical concepts in the area of international and intercultural communications. These programs are in the form of online lectures, seminars, workshops and group projects The world-wide education sector, i.e. colleges/universities, educational institutions and various B'Schools offer "Student Exchange Program", that provides students with an opportunity to study in a different country culture and environment experiences. In our country majority of the students are from middleclass or lower middle-class income group. These students are not able to pay the heavy fee to join the international courses. In this context, we suggest that educational authorities in India like UGC \& AICTE etc., make obligatory to all the colleges/universities and other educational institutions to offer a cross-culture learning programs or student exchange programs for all the students of different faculty. These programs will definitely help to all in to learn the international and intercultural communications and also remove the cultural barriers.

\section{FUTURE SCOPE OF THE STUDY}

The research was limited to few developed countries, where the technology is in boom. However, this study can be conducted in the underdeveloped or developing countries where the technology is short of.

The sample size was very small i.e. 30 . Thus, a large sample size may be giving more rich results.

The findings of this study provide the great impact to IT industries, Educational organizations and MNCs as well. Our research found that there are more requirements of IT based learning software tools and apps in coming future. The educational organization will start the culture diversity learning excusive program based on technology for those who are unable

\section{ACKNOWLEDGMENT}

We acknowledge the entire researcher whose papers were referred in this study. We also thankful to our respondents all around the globe for filling the questionnaire and support us for the completion of this paper.

\section{REFERENCES}

[1] Enn Lun Yong, Understanding cultural diversity and economic prosperity in Europe: a literature review and proposal of a culture-economy framework, Asian Journal of German and European Studies volume 4, Springer Article number: 5 (2019). DOI: https://doi.org/10.1186/s40856-019-0043-3.

[2] David B. Audretsch, Maksim Belitski, Julia Korosteleva, Cultural diversity and knowledge in explaining entrepreneurship in European cities, Small Bus Econ (2019), Springer pp 1-19 https://doi.org/10.1007/s11187-019-00191-4.

[3] Michael Jones, Irit Alony, The Cultural Impact of Information Systems - Through the Eyes of Hofstede A Critical Journey, Issues in Informing Science and Information Technology Volume 4, 2000, https://doi.org/10.28945/960

[4] Enn Lun Yong, Understanding cultural diversity and economic prosperity in Europe: a literature review and proposal of a culture-economy framework, Asian Journal of German and European Studies volume 4, Springer Article number: 5 (2019). DOI: https://doi.org/10.1186/s40856-019-0043-3.

[5] David B. Audretsch, Maksim Belitski, Julia Korosteleva, Cultural diversity and knowledge in explaining entrepreneurship in European cities, Small Bus Econ (2019), Springer pp 1-19 https://doi.org/10.1007/s11187-019-00191-4.

[6] Junhao Zhang, Educational diversity and ethnic cultural heritage in the process of globalization, International Journal of Anthropology and Ethnology volume 3, Article number: 7 (2019), Springer , https://doi.org/10.1186/s41257-019-0022-x

[7] Günter K Stahl, Martha L Maznevski, Andreas Voigt, Karsten Jonsen, Unraveling the effects of 
cultural diversity in teams: A meta-analysis of research on multicultural work groups, Journal of International Business Studies, May 2010, Volume 41, Issue 4, pp 690-709, Springer https://doi.org/10.1057/jibs.2009.85

[8] Jude Smith Rachele, The Diversity Quality Cycle: driving culture change through innovative governance, AI \& SOCIETY August 2012, Volume 27, Issue 3, pp 399-416, https://doi.org/10.1007/s00146-012-0381-7

[9] Michael Jones, Irit Alony, The Cultural Impact of Information Systems - Through the Eyes of Hofstede A Critical Journey, Issues in Informing Science and Information Technology Volume 4, 2000, https://doi.org/10.28945/960

[10] J.Y. Weisinger, E.M. Trauth, The importance of situating culture in cross-cultural IT management, IEEE Transactions on Engineering Management, Volume: 50, Issue: 1 1, Feb. 2003. https://ieeexplore.ieee.org/document/1193765/citations? $\underline{\text { tabFilter}=\text { papers\#citations }}$

[11] Americo B. Cunha, Alberto G. Canen, "Requirements gathering in information technology: a Cross-cultural perspective", Professional Communication Conference 2008. IPCC 2008. IEEE International, $\quad$ pp. $\quad 1-8, \quad 2008$. https://ieeexplore.ieee.org/document/4610198

[12] Ruben Pereira, Miguel Mira da Silva, "Towards an Integrated IT Governance and IT Management Framework", Enterprise Distributed Object Computing Conference (EDOC) 2012 IEEE 16th International, pp. 191-200, 2012.

https://ieeexplore.ieee.org/document/6337250

[13] Diwakar Singh, Managing Cross-cultural Diversity: Issues and Challenges in Global Organizations, IOSR Journal of Mechanical and Civil Engineering (IOSR-JMCE) e-ISSN: 2278-1684, pISSN: 2320-334X PP 43-50 www.iosrjournals.org International Conference on RECENT TRENDS IN ENGINEERING AND MANAGEMENT 43| Page Indra Ganesan College of Engineering.

[14] Mona A. Mohamed, The role of Information Technology in the Advancement of Multinational Corporation's Intellectual Capitain, Towson University, Towson,MD, USA, International Journal of Productivity Management and Assessment Technologies, Volume 1 Issue 3. (2012).

[15] Professor Binshan Lin, Cultural Perspectives of Information Technology: The Case of China, Cross
Cultural Management: An International Journal, Vol. 3 Issue: 3, pp.12-20, (1996) doi: 10.1108/eb008410.

[16] Kerstin V. Siakas, Elli Georgiadou, Empirical Measurement of the Effects of Cultural Diversity on Software Quality Management, Software Quality Journal September 2002, Volume 10, Issue 2, pp 169180, https://doi.org/10.1023/A:1020528024624

[17] Karamjit S. Gill, Knowledge Networking in CrossCultural Settings, AI \& SOCIETY

September 2002, Volume 16, Issue 3, pp 252-277, Springer https://doi.org/10.1007/s001460200021 